\title{
ANALYSIS REVENUES OF CASING COVER BUSINESS INSLIPPER MATERIAL IN MEDAN
}

\section{ANALISIS PENDAPATAN USAHA CASE DENGAN BAHAN BAKU SENDAL DI KOTA MEDAN}

\author{
Hanifa Khairiah $^{(1)}$,Hanifa Ayu Armayani( ${ }^{(1)}$,Mahbud Farid Lubis ${ }^{(1)}$, Muhammad Ridwan $^{(1)}$ \\ Akbar ihza vito siregar ${ }^{(1)}$, \\ $\left.{ }^{1}\right)$ Mahasiswa Jurusan Agribisnis Fakultas Pertanian, Universitas Muhammadiyah Sumatera Utara \\ Jalan Kapten Mukhtar Basri No 3 Medan \\ Email : chairiah.hanifa08@gmail.com, akbarihzapsxia@gmail.com
}

\begin{abstract}
Mobile phones or cellphones are one of the most developed communication technologies in the world. Many countries in the world are competing to produce cellphones. This happens because the demand from the market is so large. Mobile phone gloves or cellphone cases as one of the accessories used by consumers for a number of reasons, including protecting cellphones from abrasions, reducing the risk of falls, for style, etc. The aim of the study was to make people's mobile phones safer from the fall because the public now lacked protecting their own cellphones, and another goal was to determine the criteria for mobile gloves to suit the needs and desires of consumers. The type of research method chosen was descriptive analysis. the method that functions to describe or give an overview of the object under study through data or samples that have been collected as it is without doing analysis and making conclusions that apply to the public ... Income at phpcase.id is interpreted as the difference between the amount of revenue and costs incurred (total cost. Table 5 is a list of income from phpcase.id research results. Table 5. Average Business Income phpcase.id in medan city in 2019 that phpcase.id in Medan city earns income from the case business of Rp.5,200,000. Conclusion what can be taken is the product the average per pcs of the phpcase.id business in Medan city is 500 pcs with a selling price of Rp. 14,000 / pcs, the total business income of phpcase.id is Rp. 7,000,000, a variable that has a significant effect on phpcase.id's business income in the city Medan, namely raw materials, production costs and production results.
\end{abstract} Keywords : slippers,case, income,production

\begin{abstract}
Abstrak
Telepon genggam atau handphone adalah salah satu teknologi komunikasi yang paling berkembang saat ini di dunia.Banyak negara didunia berlomba-lomba memproduksi handphone. Hal ini terjadi karena demand dari pasar begitu besar. Sarung handphone atau case handphone sebagai salah satu aksesoris digunakan konsumen untuk beberapa alasan, diantaranya untuk melindungi handphone dari lecet, mengurangi resiko jatuh, untuk bergaya, dll. Tujuan dari penelitian nya adalah untuk membuat handphone masyarakat lebih aman dari kejatuhan karena masyarakat sekarang kurang melindungi handphone nya sendiri, dan tujuan lainnya adalah menentukan kriteria-kriteria sarung handphone yang sesuai dengan kebutuhan dan keinginan konsumen.Jenis metode penelitian yang dipilih adalah deskriptif analisiadalah suatu metode yang berfungsi untuk mendeskripsikan atau memberi gambaran terhadap objek yang diteliti melalui data atau sampel yang telah terkumpul sebagaimana adanya tanpa melakukan analisis dan membuat kesimpulan yang berlaku untuk umum..Pendapatan pada phpcase.id diartikan sebagai selisih antara besarnya penerimaan dan biaya yang dikeluarkan (total biaya).Tabel 5 merupakan daftar pendapatan dari hasil penelitian phpcase.id Tabel 5. Ratarata Pendapatan Usaha phpcase.id di kota medan tahun 2019bahwa phpcase.id di kota Medan memperoleh pendapatan dari usaha case tsebesar Rp.5.200.000.Kesimpulan yang dapat di ambil adalahhasil produksi ratarata per pcs dari usaha phpcase.id di kota Medan yaitu 500 pcs dengan harga jual Rp.14.000/pcs, maka total penerimaan usaha phpcase.id yaitu Rp.7000.000,Variabel yang berpengaruh signifikan terhadap pendapatan usaha phpcase.id di kota Medan yaitu bahan baku,biaya produksi dan hasil produksi.
\end{abstract}

Kata kunci: sandal, Casing, pendapatan, produksi

\section{A. PENDAHULUAN}

Perkembangan

media dalam berkomunikasi semakin lama semakin berkembang seiring perkembangannya zaman. Muncul mediamedia baru mulai dari media massa seperti televisi, radio dan lain-lain. Serta munculnya media telephone yang kabel bahkan portable. Telephone portable yang dimaksud lebih dikenal dengan mobile phone atau di Indonesia sendiri dinamakan telephone genggam (handphone). Bahkan telephone genggam yang dipasarkan pada saat ini bersifat pintar, yang dikenal dengan smartphone. Smartphone adalah telepon genggam yang mempunyai kemampuan tingkat tinggi yang sudah 
menggunakan system operasi untuk menjalankan program yang ada di dalamnya. Bahkan beberapa smartphone sekarang ini sudah mempunyai fungsi yang menyerupai 2 sebuah komputer dalam hal penggunaan perangkat keras dan perangkat lunak (Delfi, 2013: 2).

Smartphone adalah telepon yang menyatukan kemampuan-kemampuan terdepan; ini merupakan bentuk kemampuan dari Wireless Mobile Device (WMD) yang dapat berfungsi seperti sebuah komputer dengan menawarkan fiturfitur seperti personal digital assistant (PDA), akses internet, email, dan Global Positioning System (GPS). Smartphone juga memiliki fungsi-fungsi lainnya seperti kamera, video, MP3 players, sama seperti telepon biasa. Dengan kata lain, smartphone dapat dikatagorikan sebagai mini-komputer yang memiliki banyak fungsi dan penggunanya dapat menggunakannya kapanpun dan dimanapun.

Pembelajaran. Banyak penelitian telah dilakukan oleh sejumlah peneliti untuk mengidentifikasi penggunaan teknologi di antara para siswa, termasuk penggunaan smartphone. Sebagai contoh, menjelaskan 20 ide penggunaan telepon seluler di dalam kelas bahasa. Dua puluh ide ini mengijinkan para guru untuk menawarkan peningkatan pembelajaran bahasa dengan mengambil keuntungan bahwa para mahasiswa sangat familiar dan membawanya ke mana saja kapan saja waktunya.

Telepon genggam atau handphone adalah salah satu teknologi komunikasi yang paling berkembang saat ini di dunia.Banyak negara didunia berlombalomba memproduksi handphone. Hal ini terjadi karena demand dari pasar begitu besar. Di Indonesia khususnya, handphone sudah menjadi kebutuhan yang penting bagi masyarakat, baik orang tua, remaja, maupun anak-anak sudah menggunakan teknologi ini.Selain itu asesorisasesoris handphone seperti casing handphone, lampu, sarung handphone, dll juga banyak digunakan oleh konsumen untuk melengkapi handphone itu sendiri.

Sarung handphone sebagai salah satu aksesoris digunakan konsumen untuk beberapa alasan, diantaranya untuk melindungi handphone dari lecet, mengurangi resiko jatuh, untuk bergaya, dll. Tingginya permintaan akan handphone juga seharusnya diikuti oleh permintaan akan sarung handphone. Oleh karena itu kami memanfaatkan peluang bisnis untuk memproduksi sarung handphone dengan bahan limbah sendal bekal yang dari karet.

Meskipun pilihan sarung handphone yang tersedia di outlet-outlet handphone cukup banyak, tetap saja masih banyak konsumen yang tidak menggunakan sarung handphone. Dari hasil wawancara terhadap beberapa responden didapatkan beberapa alasan mengapa konsumen tidak menggunakan sarung handphone yaitu tidak adanya kesesuaian antara produk yang dihasilkan dengan keinginan konsumen misalnya : fungsi yang diinginkan pada sarung handphone tersebut tidak ada, bentuknya tidak menarik, kurang nyaman, tidak praktis, tidak mengikuti trend, malas memilih karena pilihan yang ada terlalu banyak, dll.

Dengan melihat dari perkembangan Teknologi yang semakin maju dan berkembang. Perkembangan Teknologi Handphone yang pesat ternyata mampu membuat produk yang berkaitan dengannya otomatis ikut naik pamornya. Termasuk pada aksesorisnya ini, casing hp yang pada awalnya dibuat hanya untuk melapisi hp agar tidak mudah tergores dan menjaga dari benturan.

Perilaku masyarakat pasar dalam mengonsumsi suatu produk dipasaran dapat dikatan tidak stabil, hal tersebut dikarenakan belum banyaknya inovasi produk baru yang unik, sehingga masyarakat merasa bosan dan beralih ke produk impor. Hal inilah yang akan membuat peluang pasar produk dalam negeri yang hendak berinovasi terbuka lebar. Salah satu cara yang dapat mengalihkan perhatian masyarakat adalah membuat produk yang memiliki kekhasan tersendiri, tetapi harganya dapat dijangkau masyarakat dengan pengolahan sederhana

Bisnis pernak-pernik ponsel merupakan suatu bisnis yang memiliki pangsa pasar yang luas. Hal ini dibuktikan dengan adanya dengan pengguna ponsel yang banyak, mulai dari anak-anak hingga dewasa. Dari segi perusahaan ponsel sendiri juga selalu mengeluarkan produk-produk ponsel baru dalam jangka waktu tertentu.

Disini kami membuat case protector handphone dari bahan bak sendal yang lain dari pada yang lain karena masih ada case yang belum menjamin case tersebut anti banting dan anti pecah,dan menurut penelitian kami banyak masyarakat yang mengeluh karena ketahanan dari case mereka beli sebelumnya kurang protector pada handphone mereka tersebut

Maka dari itu disini kami berinisiatif untuk memecahkan masalah dari pada masyarakat tersebut yang kurang puas pada protector case yang mereka miliki,dan disini lah kami membuat case lain dari pada yang lain dengan memanfaatkan limbah yaitu dengan menggunakan bahan baku sendal bekas,karena sendal merupakan bahan yang terbuat karet dan busa yang bahannya tidak keras untuk handphone dan tidak merusak handphone, dan ini lah yang membuat kami bisa memecahkan masalah masyarakat tersebut

Dalam kondisi lingkungan ini banyak bahan baku yang tersedia cukup banyak dan mudah didapatkan,sehingga kami yakin usaha yang kami lakukan dapat berjalan dengan baik dan lancar apabila membuka usaha softcase ini untuk masyarakat indonesia

Produk ini terbuat dari sendal bekas berbahan karet dengan ketebalan $0,7 \mathrm{~cm}$ yang akan 
membuat handphone aman dari anti pecah dan banting,dan kemudian akan dihias semenarik agar produk tersebut diminati dari berbagai kalangan masyarakat. Untuk peluang usahanya sangat memungkingkan karena untuk memperoleh bahan sendal bekas berbahan karet ini mudah ditemukan dilingkungan sekitar. Dari harga softcare ini sangat terjangkau sekai untuk anak sekolahan dan mahasiswa.

Disini strategi produk kami menganalisis pasar pada semua tahap perencanaan produk yang menyediakan informasi agar sesuai dengan kebutuhan dan keinginan konsumen yang sebelumnya sudah kami survei 8/10 dari masyarakat trutama anak sekolah dan mahasiswa lebih menyukai case yang polos dari pada yang memiliki banyak corak atau warna yang terlalu cerah.

Dan tentunya kami membuat harga yang sangat jangkau untuk masyarakat apalagi untuk kantong anak sekolah dan mahasiswa dengan harga Rp.14,000 made by order.

\section{B. METODE PENELITIAN}

Jenis metode penelitian yang dipilih adalah deskriptif analisis, adapun pengertian dari metode deskriptif analitis menurut (Sugiono: 2009; 29) adalah suatu metode yang berfungsi untuk mendeskripsikan atau memberi gambaran terhadap objek yang diteliti melalui data atau sampel yang telah terkumpul sebagaimana adanya tanpa melakukan analisis dan membuat kesimpulan yang berlaku untuk umum. Lokasi penilitian dilakukan di jalan kapten muslim gang jawan lorong muhammadiyah no 3 kecamatan medan helvetia,kota medan.Waktu kerja yang dilakukan disini $10 \mathrm{jam} /$ minggu yang artinya dalam satu hari kami memproduksi 2jam/hari

Metode Pelaksanaan dalam teknik pembuatan case,yaitu:

1) Mempersiapkan bahan baku utama,bahan baku pendukung serta alat yang digunakan saat proses produksi

2) Lalu megukur sendal dengan menyesesuaikan handphone

3) Lalu menggunting atau memotong sendal yang sudah diukur

4) Setelah itu potong hingga membentuk handphone tersebut

5) Lalu dilakukan pengeratan dengan sisa tapak dari sendal

6) Melakukan mengencatan atau penghiasan pada sendal tersebut

7) Lalu produk siap dikemas dan dipasarkan

\section{a. Analisis SWOT}

SWOT adalah singkatan dari kata-kata Strength (kekuatan perusahaan) Weaknesses (kelemahan perusahaan), Opportunities (peluang bisnis) dan Threats (hambatan untuk mencapai tujuan). Analsis SWOT digunakan untuk melihat kekuatan, kelemahan, peluang dan ancaman yang akan dihadapi oleh perusahaan. Dengan melihat kekuatan yang dimiliki serta mengembangkan kekuatan tersebut dapat dipastikan bahwa perusahaan akan lebih maju dibanding pesaing yang ada.

\section{b. Analisis Ekonomi usaha. \\ Harga Pokok Produksi}

$\mathrm{HPP}=($ Biaya Operasional + penyusutan alat 5 bulan)

Jumlah produk

\section{Harga}

Harga jual $=$ Harga Pokok + keuntungan 50\%

\section{Keuntungan}

Keuntungan $=$ pendapatan - biaya produksi

Kelayakan Bisnis dengan

$$
\mathbf{R} / \mathbf{C}
$$

\section{c. Strategi Pemasaran}

Strategi pemasaran adalah salah satu cara memenangkan keunggulan bersaing yang berkesinambungan baik itu untuk perusahaan yang memproduksi barang atau jasa. Strategi pemasaran dapat dipandang sebagai salah satu dasar yang dipakai dalam menyusun perencanaan perusahaan secara menyeluruh. Dipandang dari luasnya permasalahan yang ada dalam perusahaan, maka diperlukan adanya perencanaan yang menyeluruh untuk dijadikan pedoman bagi segmen perusahaan dalam menjalankan kegiatannya

\section{HASIL DAN PEMBAHASAN a. analisis SWOT}

Analisis SWOT adalah sebuah teknik strategi dalam mengevaluasi kekuatan, kelemahan, peluang serta ancaman yang hal ini dapat diterapkan untuk kegiatan meliputi bisnis dan usaha, pendidikan, proyek atau bahkan pada diri sendiri.

Metode analisis SWOT bisa dianggap sebagai metode analisis yangg paling dasar, yang bermanfaat untuk melihat suatu topik ataupun suatu permasalahan dari 4 empat sisi yang berbeda.Hasil dari analisa biasanya berupa arahan ataupun rekomendasi untuk mempertahankan kekuatan dan untuk menambah keuntungan dari segi peluang yang ada, sambil mengurangi kekurangan dan juga menghindari ancaman. Jika digunakan dengan benar, analisis ini akan membantu untuk melihat sisi-sisi yang terlupakan atau tidak terlihat selama ini. Dari pembahasan diatas tadi, analisis SWOT 
merupakan instrumen yang bermanfaat dalam melakukan analisis strategi. Analisis ini berperan sebagai alat untuk meminimalisasi kelemahan yang terdapat dalam suatu perusahaan atau organisasi serta menekan dampak ancaman yang timbul dan harus dihadapi.

Adapun Analisis SWOT Pada Usaha PHP adalah sebagai berikut:

\section{$>$ Strengths (kekuatan) produk}

1) Menggunakan sendal bekas yang berdampak positif terhadap lingkungan

2) Harga yang ramah dikantong dibandingkan harga softcase pada umumnya yang mencapai Rp.40,000 sampai dengan Rp.80,000

\section{$>$ Weaknesses (kelemahan)}

1) Belum banyak masyarat menggunakan dan mengetahui produk PHP

2) Dampak dari protector ini dapat membuat handphone tahan banting dan anti pecah

\section{Opportunities (peluang)}

1) Banyaknya masyarakat sekarang menggunakan handphone

2) Produk dapat dijual-belikan melalui media online karena dinilai masyarakat praktis

3) Memasarkannya langsung kepada masyarakat

\section{$>$ Threats(Ancaman)}

Memiliki banyak pesaing namun tidak terlalu dikhawatirkan dapat ancaman dari usaha ini,dikarnakan belum banyak yang menjamin melndungi handphone tahan banting dan antipecah yang menjual dengan harga murah.

\section{b. Analisis Ekonomi usaha}

\section{Harga Pokok Produksi}

harga pokok produksi adalah akumulasi dari biaya yang dikeluarkan untuk menghasilkan produk dan kemudian dibebankan pada produk

Untuk menetukan harga pokok produksi (hpp) itu sendiri bisa di lakukan dengan cara:

HPP $=$ (Biaya Operasional + Penyusutan alat 5bulan)

$$
\text { Jumlah Softcase }
$$

$$
\begin{aligned}
& =\frac{\mathrm{Rp} \cdot 3,200,000+100,000}{500} \\
& =\mathrm{Rp} \cdot 6600
\end{aligned}
$$

\section{Harga}

Harga jual yang diberikan untuk satu softcase PHP adalah: Keuntungan yang diinginkan sebanyak $100 \%=100 \% \times 6,600=6,600$ Harga jual $=$ Harga pokok + Keuntungan yang diinginkan $=6,600+$ $6,600=$ Rp. $13,200=$ Rp.14.000 Dengan harga
Rp.14,000 perproduk PHP sangat terjangkau dikantong masyarakat dibandingkan dengan produk softcase yang lain mencapai $\mathrm{Rp}, 40,000$ sampai $\mathrm{Rp}, 80,000$. Dalam membuat satu produk PHP ini memerlukan $100 \mathrm{~kg}$ sendal bekas yang akan dibuat sehingga memerlukan waktu 5bulan dapat menghasilkan 500 unit softcase.Hasil penjualan 5bulan $=500 x$ Rp. $14,000=$ Rp.7,000,000

\section{Keuntungan}

Adapun keuntungan PHP yaitu sebagai berikut: = Pendapatan - Biaya produksi $=7,000,000$ $3,200,000=$ Rp. $3,800,000$

Kelayakan Bisnis

Pada dasarnya sebuah proyek akan dikatakan layak untuk dijalankan apabila nilai R/C yang didapatkan lebih besar daripada 1. Hal ini terjadi karena semakin tinggi nilai $\mathrm{R} / \mathrm{C}$ dari sbuah proyek, maka tingkat keuntungannya yang akan didapatkan suatu proyek juga akan semangkin tinggi.

Untuk mencari ratio itu sendiri di hitung dengan rumus:

$$
\begin{aligned}
\mathrm{R} / \mathrm{C} & =\text { Penerimaan Total / Total Biaya } \\
& =7.000 .000 / 3.200 .000 \\
& =2,1 \\
& \text { Jika R/C }>1,
\end{aligned}
$$

Didapatkan bahwa R/C nya lebih dari satu, maka usaha ini dikatakan layak untuk dijalankan

\section{c.Teknik Pemasaran}

Adapun teknik pemasaran produk PHP adalah : 1) Produk Dalam strategi produk kami menganalisis pasar pada semua tahap perencanaan produk yang menyediakan informasi agar sesuai dengan kebutuhan dan keinginan konsumen

2) Harga Disini kami membuat harga yang sangat jangkau untuk masyarakat apalagi untuk kantong anak sekolah dan mahasiswa dengan harga Rp. 14,000

3) Tempat Dalam strategi tempat kami menggunakan tempat kami sewa dan kami menggunakan penjualan online

4) Promosi Dalam promosi disini kami tidak hanya melalui mulut kemulut tetapi kami mempromosikan melalui online dalam media sosial seperti instagram,facebook,dll

\section{d.Peluang Pasar}

Usaha kami memiliki peluang yang sangat besar,karna disini kami menjanjikan case handphone saat ini dimana telah berubah dari yang sebelumnya konsumen hanyan menginginkan aksesoris saja tapi disini kami membuat rancangan suatu produk yang dibutuhkan oleh konsumen tersebut,dan case ini kami rancang ekonomis untuk masyarat apalagi untuk anak sekolah dan mahasiswa 
Hipotesis Pertama

TC $=$ TFC + TVC $($ Soekartawi, 2005)

Keterangan :

$\mathrm{TC}=$ Total biaya $(\mathrm{Rp})$

TVC $=$ Total biaya variabel $(\mathrm{Rp})$

$\mathrm{TFC}=$ Total biaya tetap $(\mathrm{Rp})$

Penerimaan menurut soekartawati (2002)

$$
\mathbf{T R}=\mathbf{Q} \times \mathbf{P}
$$

Keterangan :

$\mathrm{TR}=$ Penerimaan total $(\mathrm{Rp})$

$\mathrm{Q}=$ Jumlah produksi yang dihasilkan $(\mathrm{Kg})$

$\mathrm{P} \quad=$ Harga (Rp)

Pendapatan menurut soekartawi (2002) yaitu :

$$
\begin{aligned}
& \text { NR }=\text { TR }- \text { TC eksplisit } \\
& \text { TR }=\mathbf{Q} \times \mathbf{P} \\
& \text { TC }=\text { TFC + TVC }
\end{aligned}
$$

Keterangan :

$\mathrm{TR}=$ Penerimaan total $(\mathrm{Rp})$

$\mathrm{TC}=$ Total biaya $(\mathrm{Rp})$

$\mathrm{Q}=$ Jumlah produksi yang dihasilkan $(\mathrm{Kg})$

$\mathrm{P}=$ Harga $(\mathrm{Rp})$

$\mathrm{TVC}=$ Total biaya variabel $(\mathrm{Rp})$

TFC =Total biaya tetap $(\mathrm{Rp})$

Pengujian Hasil Analisis Hipotesis Pertama

Guna menguji hopotesis pertama yaitu diduga tingkat pendapatan dari usaha case lebih besar dari biaya yang dikeluarkan digunakan analisis biaya,penerimaan dan pendapatan.

\section{Biaya Tetap (Fixed Cost)}

Biaya tetap (fixed cost) adalah biaya yang tidak berpengaruh oleh besar kecilnya produksi yang dihasilkan.Biaya tetap pada analisis pendapatan case di medan dapat dilihat sebagai berikut dalam tabel 1.Tabel 1. Rata-rata Biaya Tetap (Fixed Cost) Usaha case phpcase.id di Medan tahun 2019.

\begin{tabular}{|l|l|}
\hline Keterangan & Jumlah (Rp) \\
\hline Sewa tempat produksi & 500.00 \\
\hline Biaya penyusutan alat & 100.000 \\
\hline Biaya Tetap & 600.000 \\
\hline
\end{tabular}

Berdasar Tabel 1. Biaya sewa tempat produksi sebesar Rp 500.000 dan biaya penyusutan peralatan sebesar Rp 100.000.Biaya penyusutan peralatan dihitung berdasarkan nilai penyusutan peralatanperalatan yang digunakan dalam usha case phpcase.id tersebut.

\section{Biaya Variabel (Variabel Cost)}

Biaya variabel (variabel cost) adalah biaya yang dikeluarkan dalam proses produksi yang sebesarnya berubah-ubah tergantung dari besar kecilnya produksi.Biaya variabel pada analisis pendapatan case phpcase.id meliputi biaya bahan baku dan biaya tenaga kerja.Biaya variabel ini dalam usaha phpcase.id di medan dapat lihat pada Tabel 2. Rata-rata Biaya Variabel (Variabel Cost) Usaha case phpcase.id di Medan tahun 2019.

\begin{tabular}{|l|l|}
\hline Keterangan & Jumlah (Rp) \\
\hline Biaya bahan baku & 700.000 \\
\hline
\end{tabular}

\begin{tabular}{|l|l|}
\hline Biaya tenaga kerja & 500.00 \\
\hline Biaya variabel cost & 1.200 .000 \\
\hline
\end{tabular}

Berdasarkan tabel 2, rata-rata biaya bahan baku sebesar Rp.700.000.Bahan baku yang digunakan dalam usaha phpcase.id ini yaitu bahan baku sendal yang berbahan sendal karet atau sendal busa.Biaya tenaga kerja pada penelitian usaha phpcase.id ini Rp.500.000,waktu kerja yang dibutuhkan disini yaitu $2 \mathrm{jam} / \mathrm{minggu}$ setelah pulang kuliah.

\section{Biaya Total (Total Cost)}

Biaya Total merupakan biaya dari penjumlahan Fixed Cost (FC) dan Variabel Cost (VC) yang digunakan dalam proses produksi.Dari hasil penelitian pada phpcase.id maka didapatkan hasil seperti pada Tabel 3 .

Tabel 3. Rata-rata Biaya Total Usaha Phpcase.id di Medan Tahun 2019

\begin{tabular}{|l|l|}
\hline Keterangan & Jumlah (Rp) \\
\hline Biaya tetap/fixed cost & 600.000 \\
\hline $\begin{array}{l}\text { Biaya variabel/variabel } \\
\text { cost }\end{array}$ & 1.200 .000 \\
\hline Biaya Total / total cost & 1.800 .000 \\
\hline
\end{tabular}

\section{Penerimaan}

Penerimaan usaha phpcase.id merupakan hasil kali antara kuantitas case yg dihasilkan dalam 1pcs dan harga jual case dalam satuan rupiah(Rp).Tabel 4 merupakan hasil penerimaan dari penelitian di kota Medan.Dalam penelitian ini,total penerimaan didapatkan dari mengalikan jumlah produksi case yang didapat dikalikan dengan harga case yang berlaku,yaitu harga case per pcs sebesar Rp.14.000.Pada Tabel 4 menunjukan penerimaan dari masyarakat dalam memproduksi 500pcs yaitu Rp 7.000.000

Tabel 4. Rata-rata Produksi dan Penerimaan Total Usaha cphpcase.id di kota medan tahun 2019

\begin{tabular}{|l|l|}
\hline Keterangan & Jumlah (Rp) \\
\hline Produksi(kg) & 500 \\
\hline Harga(pcs) & 14.000 \\
\hline Penerimaan & 7.000 .000 \\
\hline
\end{tabular}

\section{Pendapatan}

Pendapatan pada phpcase.id diartikan sebagai selisih antara besarnya penerimaan dan biaya yang dikeluarkan (total biaya).Tabel 5 merupakan daftar pendapatan dari hasil penelitian phpcase.id

Tabel 5. Rata-rata Pendapatan Usaha phpcase.id di kota medan tahun 2019

\begin{tabular}{|l|l|}
\hline Keterangan & Jumlah (Rp) \\
\hline Tptal penerimaan & 7.000 .000 \\
\hline Total penerimaan & 1.800 .000 \\
\hline Pendapatan & 5.200 .00 \\
\hline
\end{tabular}

Berdasarkan Tabel 9, dapat ditarik kesimpulan bahwa phpcase.id di kota Medan memperoleh pendapatan dari usaha case tahun 2019 sebesar Rp.5.200.000. 
Hanifa Khairiah, Hanifa Ayu Armayani, Mahbud Farid Lubis, Muhammad Ridwan' Akbar ihza vito siregar

Pada peluang usaha kami ini ,kami memiliki peluang yang sangat besar,karna disini kami menjanjikan case handphone saat ini dimana telah berubah dari yang sebelumnya konsumen hanyan menginginkan aksesoris saja tapi disini kami membuat rancangan suatu produk yang dibutuhkan oleh konsumen tersebut,dan case ini kami rancang ekonomis untuk masyarat apalagi untuk anak sekolah dan mahasiswa.

Disini kami menjual harga yang aman untuk dikantong masyarakat terutama anak sekolah dan mahasiswadari pada dengan dibandingkan harga softcase pada umumnya yang mencapai Rp.40,000 sampai dengan Rp.80,000 bahkan Rp.200.000 untuk case protector handphone.

\section{KESIMPULAN}

1. Biaya dari usaha phpcase.id di kota Medan yaitu biaya tetap Rp.500.000 dan biaya variabel Rp.1.200.00

2. Hasil produksi rata-rata per pes dari usaha phpcase.id di kota Medan yaitu 500 pcs dengan harga jual Rp.14.000/pcs,maka total penerimaan usaha phpcase.id yaitu Rp.7000.000

3. Pendapatan usaha phpcase.id di kota medan yaitu penerimaan Rp.7.000.000 dikurangin biaya total Rp.1.800.000. sehingga diperoleh pendapatan sebesar Rp.5.200.000

4. Variabel yang berpengaruh signifikan terhadap pendapatan usaha phpcase.id di kota Medan yaitu bahan baku,biaya produksi dan hasil produksi.

5. Php case terbuat dari sendal bekas yang memanfaatkan limbah sekitar lingkungan.

\section{SARAN}

1. Diharapkan penelitian ini dapat digunakan sebagai referensi sekaligus bahan bacaan bagi masyarakat yang bermasalah dalam melindungin handphone dari anti banting untuk meningkatkan kualitas dan kuantitas handphone

2. Diharapkan peneliti selanjutnya dapat menggunakan alat pemotong atau pencetak case handphone tersebuat agar lebih bagus dan cepat.

\section{DAFTAR PUSTAKA}

Delfi ,Andre.2013.SMARTPHONE SEBAGAI GAYA HIDUP (Studi Deskriptif Tentang Penggunaan Smartphone Sebagai Gaya Hidup Mahasiswa FISIP USU).

Soekartawi.2002.AnalisisUsahatani.Jakarta.Univers itas Indonesia Press.

Soekartawi.(2005).AnalisisUsahatani.Jakarta.UI Press.

Sugiyono, 2009, Metode Penelitian Kuantitatif, Kualitatif dan R\&D, Bandung : Alfabeta. 